\title{
SARS and Kiribati: Eyes wide open
}

\author{
Zimmerman Peta-Anne', Yeatman Heather ${ }^{1}$, Jones Michael2 ${ }^{2}$, Murdoch Helen ${ }^{3}$ \\ 1. Faculty of Health and Behavioural Sciences, University of Wollongong, NSW, Australia \\ 2. Faculty of Commerce, University of Wollongong, NSW, Australia \\ 3. Ministry of Health, Republic of Kiribati
}

\begin{abstract}
A comprehensive infection prevention and control programme (IPCP) is designed to control and prevent the transmission of infectious diseases within the healthcare environment and the community. Understanding how an IPCP is introduced within a health system can inform actions to encourage their adoption in other locations. This paper explores the adoption stages of an IPCP in a specific case situation of SARS.
\end{abstract}

Data sources and analysis included: 1) Chronological and thematic analysis of IPCP documentation and assessments performed by local staff and external agencies/consultants, and 2) semi-structured interviews with local key informants and external agencies (using snow-ball sampling) with thematic analysis. Analysis was performed according to Everett Rogers' Diffusion of Innovations for Organisations framework.

The two key activities of the organisational innovation process were identified. These were: initiation and implementation. The initiation activity included: 1 ) agenda-setting: preparations for severe acute respiratory syndrome (SARS) in 2003 stimulated the identification of organisational IPCP deficits, and 2) matching: deficits were identified and the decision to adopt an IPCP innovation package was made. Implementation included: a) redefining/restructuring: identification of the components of an IPCP and how they best fit within the local health structure, b) clarifying: integration of IPCP into the health services and defining an infection control role within the nursing division and, c) routinising: the IPCP became an ongoing element in health service delivery.

\section{Corresponding author}

Peta-Anne Zimmerman

Faculty of Health and Behavioural Sciences, University of Wollongong, Wollongong, NSW, 2522, Australia

Email: petaanne.zimmerman@gmail.com or papz832@uowmail.edu.au 
The adoption of the IPCP followed the classic Diffusion of Innovations Process for Organisations. The case study described serves as an example of IPCP adoption model in other low- and middle-income healthcare settings and suggests ways to utilise opportunities as they present.

\section{Key words}

SEVERE ACUTE RESPIRATORY SYNDROME - prevention and control; INFECTION CONTROL - organization and administration, methods

\section{Background}

An infection prevention and control programme (IPCP) is a collection of activities, resources, policies and procedures designed to control and prevent the transmission of infectious diseases within the healthcare environment and the community. ${ }^{1}$

\section{The Republic of Kiribati}

The Republic of Kiribati is a central western Pacific country of 33 atolls and reef islands in three main island groups, the Gilbert, Phoenix and Line Islands. Kiribati has a total land mass of 811 square kilometres spread over 3.5 million kilometres of ocean. It has a population of approximately 100000 and an annual population growth rate of $1.7 \%$. The most populated islands are South Tarawa, North Tarawa and Kiritimati Island with urban growth rates of $5.2 \%, 4.8 \%$ and $8 \%$ respectively. ${ }^{2}$ Compared to most other Pacific islanders, I-Kiribati (inhabitant of Kiribati) have a short life expectancy with 65 years for males and 70 years for females. ${ }^{2}$

The health system of Kiribati is publicly funded with government spending $\$ 13.45$ million USD in 2008, primarily on curative services, pharmaceuticals and staffing. ${ }^{2}$ Significant technical and financial assistance is provided to the Ministry of Health by development partners. ${ }^{3}$ The formal health system is administered by the central Ministry of Health. Traditional healers provide a parallel service offering local medicines, massage, antenatal, childbirth and postnatal care. Most people use both services though there is no coordination between them. Primary health care is provided through a network of 92 health centres and dispensaries. Basic hospital services are available at South Tarawa (Betio), Kiritimati Island and North Tabiteuea. Secondary care is provided by the national referral hospital in South Tarawa. Patients requiring tertiary care services may be referred overseas for treatment if they meet the criteria defined by the Ministry of Health.

Environmental factors such as overcrowding of urban areas, particularly in South Tarawa, are increasing the risk of transmission of infectious disease. Other factors such as poor water quality, inadequate water supply, inconsistent personal hygiene practices, poor sanitation, food handling and storage practices contribute to communicable disease transmission. The incidence of tuberculosis per 100000 population in Kiribati is now the second highest in the Pacific. ${ }^{4}$ The Western Pacific Regional Office of WHO reports 365/100 000 population in Kiribati compared with 108/100 000 population in the region. ${ }^{4}$ In Kiribati, 70\% of reported TB cases are found in Betio, South Tarawa. ${ }^{2}$ In 2005, diarrhoeal disease and respiratory infections were the leading causes of morbidity amongst adults and mortality amongst children. ${ }^{3}$ The WHO has found that data suggest non-communicable disease incidence is increasing, making the severity of communicable diseases potentially worse for individuals with chronic disease processes. In addition, poor community knowledge regarding infection prevention practices is likely to be reflected in poor staff practices within healthcare settings.

\section{Methods}

To gain an understanding of the process of adoption of IPCPs requires exploration of the process itself, not just whether programme components are in place. To assist in understanding this process, an examination of the evolution of the IPCP in the Republic of Kiribati was conducted. As this was an exploration of how an IPCP, as a group of activities and components, had 
been adopted over time, it was examined through the Diffusion of Innovations framework. ${ }^{5}$

Data which assist in the investigation of the innovation process in an organisation include the recollections of key participants in the process, written documentation of the organisation about the adoption decision and process and other data sources. ${ }^{5}$

With the co-operation and permission of the Ministry of Health of the Republic of Kiribati, collaboration was established with the Infection Control Principal Nursing Officer (ICPNO). In consultation with the ICPNO, a review of relevant infection control documentation was performed and a series of seven interviews were conducted with key stakeholders in the IPCP.

\section{IPCP documentation analysis}

A chronological and thematic analysis of Republic of Kiribati IPCP documentation (for example: infection control manuals and Infection Control Committee minutes) was undertaken. This analysis was supplemented with further analysis of the findings and recommendations of IPCP assessments as performed by Republic of Kiribati staff and external agencies/consultants. The analysis was guided by the key elements and stages of the innovation process in organisations. ${ }^{5}$ The document review was conducted by the researcher while in Kiribati. Analysis of these documents was performed to provide a descriptive timeline of the process of IPCP adoption in Kiribati. The data were cross referenced against available reports and recommendations of external agencies/consultants to determine whether changes had occurred after the provision of technical guidance. This served to identify the stages of the innovation process.

\section{Interviews}

Interviews were conducted with available key stakeholders in the Ministry of Health, infection prevention and control personnel, senior nursing, medical and laboratory staff. There were no refusals to participate. From these interviews a snow-balling technique was used to identify other key stakeholders who had been involved in the development of the Kiribati IPCP and interviews were sought with these individuals. ${ }^{6}$ Each stakeholder was interviewed individually. The interviews were semi-structured following an interview schedule. Interviews were audio-recorded and transcribed by the researcher. The interviews averaged 40 minutes in length. Data were subjected to thematic analysis.

Piloting of the interview schedule for comprehension and language suitability was conducted with an infection prevention and control professional from a similarly resourced IPCP in the Pacific. Written consent for the interviews was sought and received from all interview participants in accordance with the requirements of the University of Wollongong Human Research Ethics Committee.

\section{Thematic analysis}

All data were subjected to thematic analysis "as a means of re-organising the data according to conceptual themes recognised by the researcher" $p$. $255 .{ }^{6}$

Thematic analysis involved the search for and identification of common themes throughout the document reviews and interviews. ${ }^{7}$ This involved reading, overviewing, and annotating the text prior to systematic coding. ${ }^{8}$ The data were explored for words that were used, concepts discussed, linguistic devices utilised and non-verbal cues identified by the researcher during the interview process. ${ }^{8}$ To explore word-related themes the text was systematically searched to find all instances of a particular word or phrase, making note of its context or meaning. ${ }^{8}$ Livescribe hardware and NVivo9 software were used in the collection and organisation of data for analysis. ${ }^{9,10}$

Concepts that were primarily used to explore the innovation process were the four components of the Diffusion of Innovations theory: the innovation, communication channels, time and the social system. ${ }^{5}$ Other concepts and themes that emerged from the data in addition to these components were equally analysed.

By investigating and analysing the phenomena in this way it was expected that information would be gathered to identify the five stages of the innovation decision process as well as the sequences, divergent and parallel paths, feedback and feed forward cycles in the process. ${ }^{5,11}$ 


\section{Results}

The IPCP documentation provided chronological and thematic information covering the period: 2000 to 2010. Documents analysed during the review process included: reports from external agencies, Infection Control Committee minutes, programme documentation, internal review reports, staff health records, education records, minutes of other communicable disease committees, strategic plans, implementation plans and guidelines. This information provided the chronological framework to identify the significant events which informed the adoption process.

The interviews $(\mathrm{N}=7)$ provided further identification of key points in the innovation process and personal insights into the other events and actions of individuals, which were not identifiable from the documentation. Table I provides a summary of the key events and results that shaped the current IPCP in Kiribati.

\section{Pre 2003-2005}

The documentation review found no reference to any IPCP activities prior to 2003. In 2003, the world experienced the Severe Acute Respiratory Syndrome (SARS) outbreak, which was focused in the Asia Pacific region. This resulted in a SARS Task force being established in Kiribati, preparedness training for health staff and an assessment of public health and infection control preparedness being conducted, as detailed in Table 1. All interview participants noted SARS as a significant event in the adoption of the IPCP. One interview participant provides a clear example of this.

P2: "It especially started with the SARS ...there was not even a programme of infection control at that time."

There was no documentary evidence available for 2004, yet interview participants identified this was the year that a comprehensive IPCP was first conceptualised by a senior nursing officer.

P3: "Okay - actually there was one nurse, [name withheld], I think she did her Masters in [overseas country], and then she came back with the idea of creating this [IPCP] programme. ... I think that's the first, .. 2004."
All interview participants identified 2005 as the year the IPCP came into being. This was supported by a number of IPCP documents. After a proposal was made to a donor organisation, assistance was provided in the form of a short term consultant (STC) in May of that year. Six of the seven interviewees identified this as a significant event. A number of activities stemmed from the involvement from the STC as detailed in Table I. The events of 2005 ultimately resulted in the beginnings of a comprehensive IPCP. This included the establishment of an Infection Control Committee at the facility level.

\section{6-2009}

In 2006 the ICC became multi-disciplinary and took on a national role in guiding practice with the IPCP progressively being implemented in all levels of healthcare. This included education, occupational exposure management and hand hygiene initiatives. These initiatives consisted of IEC materials, training sessions and the introduction of alcohol based hand hygiene products provided by donor organisations. The hand hygiene initiatives were based on resources provided by the STCs and the WHO.

One of the most significant events between 2006 and 2009 was the establishment of a programme to vaccinate health care workers for hepatitis $B$ as part of the occupational exposure management initiative. In 2006 a proposal for the vaccination of health care workers for hepatitis B was developed in consultation with the $\mathrm{WHO}$ and UNICEF.

P3: "The end of 2006 they proposed for the more vaccines for hepatitis for health care workers, and then early May 2007 we started off."

In 2007 the hepatitis B vaccination programme for health care workers was introduced. This incorporated immune status testing of staff prior to vaccination for hepatitis B which was able to be performed locally. This programme was administered and organised by the ICPNO who assumed the role of the occupational exposure co-ordinator.

\section{9-present}

During this period it was recognised there was a need to identify separate funding for alcohol based 
Table I. Factors contributing to the development of the Kiribati IPCP

\begin{tabular}{|c|c|c|}
\hline Year & Activities/events & Findings/results \\
\hline Pre 2003 & $\begin{array}{l}\text { - Persistent Organic Pollutants } \\
\text { (POPs) review }\end{array}$ & $\begin{array}{l}\text { - Absence of infection control committee or } \\
\text { personnel }\end{array}$ \\
\hline 2003 & $\begin{array}{l}\text { - SARS rapid preparedness assessment } \\
\text { - SARS taskforce establishment and activities }\end{array}$ & $\begin{array}{l}\text { - Limited infection control awareness and practice } \\
\text { - Absence of an infection control programme }\end{array}$ \\
\hline 2004 & - Senior nurse recognises need for an IPCP & - Need for a comprehensive IPCP identified \\
\hline 2005 & $\begin{array}{l}\text { - Proposal made to donor for assistance } \\
\text { to develop IPCP } \\
\text { - Short term consultant (STC) visits } \\
\text { - Limitations assessment of the } \\
\text { health services performed by senior } \\
\text { nursing staff } \\
\text { - Provision of resources, } \\
\text { mentoring to ICC and ICPNO } \\
\text { - Further recommendations made } \\
\text { by STCs to expand the scope of the IPCP }\end{array}$ & $\begin{array}{l}\text { STC - outcomes of visit: } \\
\text { - Train the trainer workshop for senior nursing } \\
\text { officers } \\
\text { - Nursing based infection control committee } \\
\text { established } \\
\text { - Infection control manual written by staff } \\
\text { - Training of other health care staff } \\
\text { - IEC development } \\
\text { - Infection control principal nursing officer (ICPNO) } \\
\text { role established } \\
\text { - IPCP action plan developed } \\
\text { - Internal risk assessment and audit } \\
\text { - Occupational exposure management programme } \\
\text { established }\end{array}$ \\
\hline 2006 & $\begin{array}{l}\text { - Multi-disciplinary ICC directing } \\
\text { national practices established } \\
\text { - Annual IPCP work plan } \\
\text { - Surveillance plan } \\
\text { - Hepatitis B vaccination programme } \\
\text { proposed }\end{array}$ & $\begin{array}{l}\text { - Work plan implemented } \\
\text { - Recognition of the IPCP by hospital management } \\
\text { committee }\end{array}$ \\
\hline 2007 & $\begin{array}{l}\text { - Annual review of work plan } \\
\text { - Expansion of ICPNO role } \\
\text { - Education programme reviewed }\end{array}$ & $\begin{array}{l}\text { - Hepatitis B vaccination programme implemented } \\
\text { - New education programme developed and } \\
\text { implemented }\end{array}$ \\
\hline 2008 & $\begin{array}{l}\text { - Annual review of education } \\
\text { programme and work plan } \\
\text { - Ministry of health clinical service plan } \\
\text { included IPCP activities for first time } \\
\text { - Infection control manual reviewed } \\
\text { - Occupational exposure surveillance } \\
\text { data regularly reported at ICC and senior } \\
\text { management meetings }\end{array}$ & $\begin{array}{l}\text { - Hand hygiene initiatives developed } \\
\text { - Targeting of education to specific healthcare } \\
\text { workers }\end{array}$ \\
\hline
\end{tabular}




\begin{tabular}{|c|c|c|}
\hline 2009 & $\begin{array}{l}\text { - H1N1 preparedness activities } \\
\text { - Annual review of IPCP } \\
\text { - Syndromic surveillance activities } \\
\text { - Direct reporting of surveillance } \\
\text { activities to the ministry of health }\end{array}$ & $\begin{array}{l}\text { - Development and distribution of hand hygiene } \\
\text { and occupational exposure IEC to all health } \\
\text { facilities } \\
\text { - Further targeting of education } \\
\text { - H1N1 vaccination completed }\end{array}$ \\
\hline 2010 & $\begin{array}{l}\text { - Baseline survey of infection } \\
\text { control practices } \\
\text { - Waste management and cleaning } \\
\text { plans reviewed } \\
\text { - Surveillance plan to include surgical } \\
\text { site infections }\end{array}$ & $\begin{array}{l}\text { - Action plans developed and implemented based } \\
\text { on survey and review findings } \\
\text { - Water quality testing implemented based on } \\
\text { surveillance findings } \\
\text { - HIV specialist medical officer permanently } \\
\text { attached to occupational exposure management } \\
\text { programme }\end{array}$ \\
\hline
\end{tabular}

hand rubs and not to rely on donor organisations. Syndromic surveillance of communicable disease and water availability was added to the IPCP and direct reporting was established with the Ministry of Health.

\section{Discussion}

The value of reporting the evolution of an IPCP in a low- and middle income country (LMI) is to identify a model that can explain how it came to be. By identifying such a model this can then serve to assist similar health environments to exploit opportunities which may present themselves. In the case of Kiribati this opportunity was created by SARS.

Based on the outcomes of the interviews and documentation analysis it is clear there was a staged progression of the IPCP. The Diffusion of Innovations framework is thus relevant to how the IPCP was adopted in the Republic of Kiribati, as shall be discussed.

The IPCP adoption in Kiribati included sequences and response to stimulus from external and internal sources, consistent with Rogers' staged process of initiation and implementation, as illustrated in Figure 1. $5,11,12$

Initiation of the IPCP involved both agenda-setting and matching. In Kiribati this agenda-setting stage appears to have occurred in the years up to and including 2003. It is in this stage that the identification and prioritisation of needs and problems occurs resulting in the search within the organisation for innovativeness to meet these problems. ${ }^{5}$ Innovations result not from a single incident, though a shock, such as SARS, can provide the opportunity to address an already known performance gap and initiate the innovation process. Normally this would occur through a sequence of events which culminate in a force for change. ${ }^{13}$

The matching stage within the Kiribati case study emerges in a sequence of events after the shock of SARS in 2003 and up to and including 2005. This resulted in a decision to rectify the infection control performance gap with the IPCP innovation. Successfully matching the problem to the innovation is essential to its success and sustainability, particularly within healthcare organisations..$^{14}$ It is at the point, after the matching has ocurred, that the decision to proceed with the innovation occurs and the implementation sub-process can begin.

Implementation of an innovation is considered by Rogers to involve three stages: redefining/ restructuring, clarifying and routinising. The year 2005 was when the implementation sub-process began in Kiribati. Through the facilitation of a STC the IPCP was adapted and changed to suit the needs of the organisation. Structural changes were also made to the organisation through the introduction of an Infection Control Committee and an ICPNO. This demonstrated a feedback and feed-forward cycle that encouraged active participation of individuals in the organisation. 


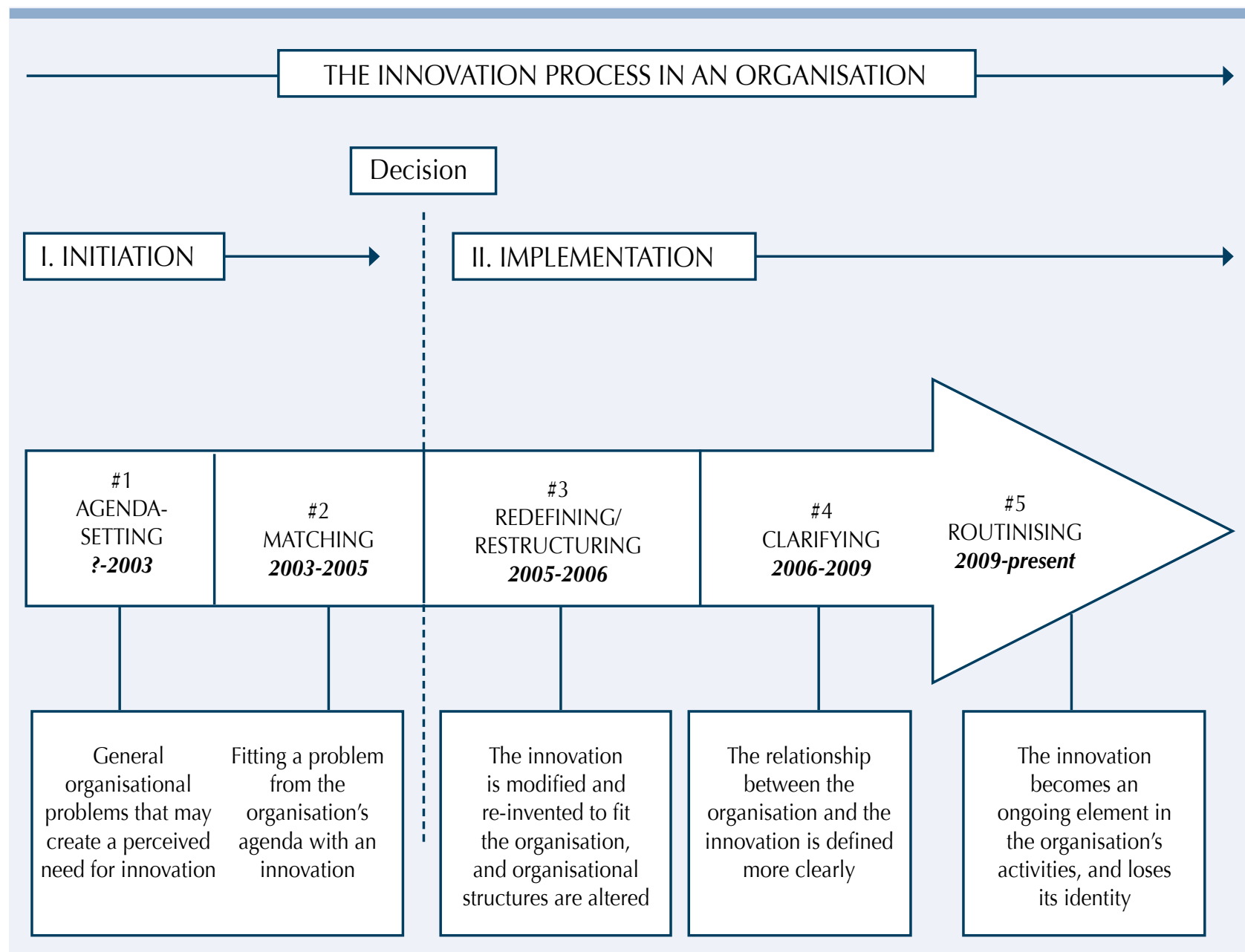

Figure 1. Five stages in the innovation process in organisations p. $421 .{ }^{5}$

Through the remainder of 2005 and 2006, redefining/ restructuring continued. One example was the change in membership of the Infection Control Committee to be more representative of the key stakeholders in the IPCP and to adopt a more nationally directed role.

Between 2006 and 2009 the Kiribati healthcare organisation utilised the IPCP to review and establish education programmes, develop quality indicators to assess compliance with the programme and provide specialist consultation and advice. The information gained from these reviews assisted in clarifying the programme and its direction. In addition, the Infection Control Committee was expanded during this stage. Its membership, from the various healthcare disciplines, became champions of the IPCP and they played a significant role in achieving acceptance of the programme.
In this Kiribati case study, participation of health care workers in the innovation process was evident and acted to routinise and thus sustain the innovation in the Kiribati health care environment. Regular IPCP activities included the assessment of compliance amongst healthcare workers through the quality indicators and continual review process. The feedback from these assessments continued to inform the programme and assisted in its routinisation in the organisation. From 2009 until the present, the activities of the IPCP continue and are accepted as part of the delivery of healthcare in Kiribati. It has now become part of the continuous quality improvement process, a fixture of the education programme, and a source of advice and information.

\section{Limitations of the study}

The information to support the premise that the Kiribati IPCP followed a Diffusion of Innovations framework was limited by the availability of documentation 
and interview participants. Prior to 2005 there is no documentary evidence of the absence or presence of an IPCP and thus information is purely dependant on the recollections of the interview participants. The researcher, though known by the organisation, is not I-Kiribati which may have had an effect on the desire to disclose by the interviewees.

\section{Conclusion}

The sequence of events and activities in the Kiribati case study clearly follows the stages of the Innovation Process in Organisations model and provides an opportunity for lessons to be learnt. ${ }^{5}$

Set the agenda: Healthcare workers and administrators should exploit the opportunities that external stimuli such as shocks to the health care system can provide, in order to introduce an IPCP.

Match the solution to the problem: Use the resources available both within and external to the healthcare system to find a suitable solution and move the innovation ahead.

Make the solution and the environment fit each other: Involve key people and healthcare workers themselves to make the IPCP applicable and unique to their healthcare environment.

Let the relationship evolve: Seek input and feedback through open communication, audits and marketing of the innovation to administrators and healthcare workers. Identify champions within the health system who can assist in its integration. Provide practical ways to demonstrate how the innovation benefits the healthcare worker and the patient.

Let it become routine: Incorporate the IPCP into the day to day work of the healthcare worker so that it becomes an integral part of health service delivery.
This case highlights the usefulness of considering the adoption of an IPCP in a healthcare organisation through the lens of a theoretical framework such as the Diffusion of Innovations model. Practical insights were gained that can serve as an IPCP adoption model in similar healthcare settings.

\section{Acknowledgements}

The authors acknowledge and thank the Ministry of Health of Kiribati and its staff for their permission and assistance in conducting this research.

\section{References}

1. Farr BM. Reasons for noncompliance with infection control guidelines. Infection Control \& Hospital Epidemiology 2000; 21(6): 411-416.http://dx.doi.org/10.1086/501783

2. World Health Organization. Western Pacific Country Health Information Profiles 2010 Revision. Manila: World Health Organization; 2010.

3. World Health Organization. Western Pacific Country Health Information Profiles 2008 Revision. Manila: World Health Organization; 2008.

4. World Health Organization. Tuberculosis control in the Western Pacific Region: 2009 Report. Manila: World Health Organization; 2009.

5. Rogers EM. Diffusion of Innovations. 5th ed. New York: Free Press; 2003.

6. Minichello V, Aroni R, Timewell E, Alexander L. In-Depth Interviewing. 2nd ed. Melbourne: Longman; 2000.

7. Morse J, Field P. Nursing Research. The application of qualitative approaches. 2nd ed. New York: Chapman and Hall; 1996.

8. O'Leary Z. The essential guide to doing research. London: Sage; 2005.

9. Livescribe [computer program]. Oakland: Livescribe Inc.; 2009.

10. NVivo9 [computer program]. Doncaster, Australia: QSR International Pty Ltd; 2010.

11. Wolfe R. Organizational Innovation: Review, critique and suggested research directions. Journal of Management Studies 1994; 31(3): 405-431. http://dx.doi. org/10.1111/j.1467-6486.1994.tb00624.x

12. Tornatzky L, Fleischer M. The Process of Technological Innovation. Lexington: Lexington Books; 1990.

13. Schroeder RG. The Development of Innovation Ideas. In: Van de Ven AH, Angle HA, Poole MS, eds. Research on the Management of Innovation: The Minnesota Studies. New York: Ballinger/Harper and Row; 1986.

14. Goodman RM, Steckler A. A Model for the Institutionalization of Health Promotion Programs. Family and Community Health 1989; 11(4): 63-78. 